\title{
O CÁRCERE BRASILEIRO E O PERFIL SOCIAL DO SISTEMA PRISIONAL DO MARANHÃO
}

Yata Anderson Gonzaga Masullo ${ }^{1}$ Janderson Rocha ${ }^{2}$ Silas Nogueira de Melo $^{3}$

Resumo: O Brasil, elevou sua taxa de aprisionamento em aproximadamente $200 \%$ nos últimos 20 anos. O objetivo deste trabalho é caracterizar o perfil socioeconômico das unidades prisionais e consolidar um acervo de informações que forneça subsídios para a proposição de políticas públicas e estratégias de monitoramento, aperfeiçoamento e fiscalização do Sistema Carcerário de uma Unidade da Federação brasileira (Maranhão). A metodologia consistiu na compilação e análise de indicadores sociais fornecidos pelo Ministério da Justiça e Departamento Penitenciário Nacional - DEPEN, Tribunal de Justiça e Secretaria Estadual de Administração Penitenciária - SEAP. Em consonância com outros estudos, nossos resultados apontam para o drama que se tornou o sistema prisional brasileiro. Seguindo a lógica brasileira, o aumento progressivo da população carcerária, devese mais a uma política de repressão e criminalização à pobreza, do que a uma política capaz de reduzir as ocorrências criminais letais ou não letais.

Palavras-chave: Sistema Prisional. Encarceramento em Massa. Brasil. Maranhão.

\section{BRAZILIAN CARRIER AND THE SOCIAL PROFILE OF THE MARANHÃO PRISON SYSTEM}

Abstract: Brazil has increased its rate of imprisonment by approximately $200 \%$ over the past 20 years. The objective of this work is to characterize the socio-economic profile of the prison units and to consolidate a collection of information that provides subsidies for proposing public policies and strategies for monitoring, improving, and inspecting the Prison System of a Brazilian Federation Unit (Maranhão). The methodology consisted of compiling and analyzing social indicators provided by the Ministry of Justice and the National Penitentiary Department - DEPEN, the Court of Justice, and the State Secretariat for Penitentiary Administration - SEAP. Supporting other studies, our results point to the drama that has become the Brazilian prison system. Following Brazilian logic, the progressive increase in the prison population is due more to a policy of repression and criminalization of poverty, than to a policy capable of reducing lethal or non-lethal criminal occurrences.

Keywords: Prison System. Mass Incarceration. Brazil. Maranhão.

\section{CARRERA BRASILEÑA Y PERFIL SOCIAL DEL SISTEMA PRISIONERO DE MARANHÃO}

Resumen: Brasil ha aumentado su tasa de encarcelamiento en aproximadamente un $200 \%$ en los últimos 20 años. El objetivo de este trabajo es caracterizar el perfil socioeconómico de las unidades penitenciarias y consolidar una recopilación de información que brinde subsidios para proponer políticas públicas y estrategias para

\footnotetext{
1 Instituto Maranhense de Estudos Socioeconômicos e Cartográficos, Departamento Estudos e Pesquisas, São Luís, Brasil, yanderson3@hotmail.com, https://orcid.org/0000-0001-5861-752X

2 Instituto Maranhense de Estudos Socioeconômicos e Cartográficos, Departamento Estudos e Pesquisas, São Luís, Brasil, jr_meta@hotmail.com, https://orcid.org/0000-0003-3940-0215

3 Universidade Estadual do Maranhão, Departamento de História e Geografia, São Luís, Brasil, silasmelo@professor.uema.br, https://orcid.org/0000-0003-3363-5208
} 
monitorear, mejorar e inspeccionar el Sistema Penitenciario de una Unidad de la Federación Brasileña (Maranhão). La metodología consistió en la compilación y análisis de indicadores sociales proporcionados por el Ministerio de Justicia y el Departamento Penitenciario Nacional - DEPEN, el Tribunal de Justicia y la Secretaría de Estado de Administración Penitenciaria - SEAP. En línea con otros estudios, nuestros resultados apuntan al drama que se ha convertido en el sistema penitenciario brasileño. Siguiendo la lógica brasileña, el aumento progresivo de la población carcelaria se debe más a una política de represión y criminalización de la pobreza que a una política capaz de reducir los sucesos criminales letales o no letales.

Palabras clave: Sistema penitenciario. Encarcelamiento masivo. Brasil. Maranhão.

\section{Introdução}

A origem do modelo vigente do sistema carcerário brasileiro, data do início do século XIX, com o surgimento de prisões com celas individuais e oficinas de trabalho (MACHADO et al., 2013). Em 1890, cria-se o Código Penal, onde fica estabelecido novas modalidades de penas, além de considerar penas restritivas de liberdade individual que não deveriam exceder trinta anos, isso culminou com a extinção das penas perpétuas e coletivas (PEDROSO, 1997).

Posteriormente, o sistema carcerário passou por diversas alterações conceituais, estruturais e legislativas até os dias atuais. Entre essas mudanças, destacam-se o Código Penitenciário da República de 1935, Código Penal Brasileiro de 1940, Lei de Execução Penal (Lei № 7.210/1984) e porque não a Constituição da República Federativa do Brasil de 1988, que incorporou questões preestabelecidas em atos normativos, reforçando aspectos ligados aos direitos humanos. Ressalta-se, que as diferentes legislações supracitadas, foram alteradas diversas vezes, sempre se adequando a ideologia preponderante da época (DULLIUS e HARTMANN, 2011).

Mesmo com os avanços obtidos em diferentes frentes, as prisões do Brasil enfrentam graves problemas conjunturais. Essa realidade, pode ser visualizada em todos os países da América Latina (Assis, 2007) e Callegari, 2009). Destaca-se, os grandes desafios a serem enfrentados, como a superlotação das celas dominadas por facções criminosas (Primeiro Comando da Capital - PCC, Comando Vermelho CV e outros), o que é amplificado pela insalubridade, proliferação de epidemias e o consumo de drogas. Para Pedroso (1997), isso revela além do descaso público, a perda do caráter retributivo, apregoado na Constituição Federal. Isso, implica no esvaziamento da execução penal (Carvalho Neto, 2016). 
Originário do contexto evidenciado, o presente estudo possui o objetivo de caracterizar o perfil socioeconômico das unidades prisionais e consolidar um acervo de informações - com base em critérios, padrões e linguagens de fácil compreensão e utilização - que forneça subsídios para a proposição de políticas públicas e estratégias de monitoramento, aperfeiçoamento e fiscalização do Sistema Carcerário do Maranhão. Deste modo, preocupa-se na realidade, em identificar indicadores sociais com base nos fluxos, tendências e evidências, que permitam otimizar os instrumentos de controle, por parte das instituições responsáveis pela administração penitenciária no Estado.

Para tanto, inicialmente caracteriza-se o sistema carcerário do Brasil por unidade da federação, entre 2000 e 2017 com base na avaliação de indicadores (quantidade de unidades prisionais; população com privação de liberdade; faixa etária; escolaridade; taxa de aprisionamento e ocupação) obtidos por meio do Ministério da Justiça e Departamento Penitenciário Nacional - DEPEN. Posteriormente, com base em dados fornecidos pelo Tribunal de Justiça e Secretaria Estadual de Administração Penitenciária - SEAP do Maranhão (2014 - 2018), analisa-se o perfil social e econômicos das unidades prisionais do Estado, considerando aspectos como concentração de presos, natureza de custódia, naturalidade, cor, sexo e escolaridade.

\section{Características do Cárcere Brasileiro}

O sistema carcerário brasileiro, demonstra os resultados do nosso modelo de política de segurança, cujos pilares são a guerra às drogas (Passos e Souza, 2011), a polícia militar (Ceccato et al., 2018) e a prisão, originando efeitos colaterais como o fenômeno denominado encarceramento em massa (Borges, 2019). Segundo Dias e Manso (2018), enquanto permanecermos neste labirinto esquizofrênico, continuaremos aprofundando o nosso histórico fosso econômico, a exclusão social e a vulnerabilidade da democracia brasileira.

Nesse contexto, observa-se que o Brasil contabiliza 748.009 pessoas privadas de liberdade, interligadas ao sistema penitenciário do País (Figura 01). Destes, 30,4\% são presos provisórios, resultando em uma taxa geral de 359,4 presos por 100 mil habitantes (INFOPEN, 2019).

Considerando, que o País possuía 442.349 vagas no sistema penitenciário (INFOPEN, 2019). Considerando o percentual de presos em regime fechado e 
provisório do Brasil, identifica-se a existência de um déficit aproximado de 147.831 vagas. Referente ao quantitativo de pessoas privadas de liberdade, verifica-se que 95\% (711.080) são do sexo masculino e 5\% (36.929) são mulheres. Sobre esse panorama, Dotti (2003) afirma que o sistema prisional Brasileiro não passa de grandes aglomerados de pessoas, vivendo em condições sub-humanas.

Figura 01- Características do cárcere brasileiro

Fonte. INFOPEN, 2016.

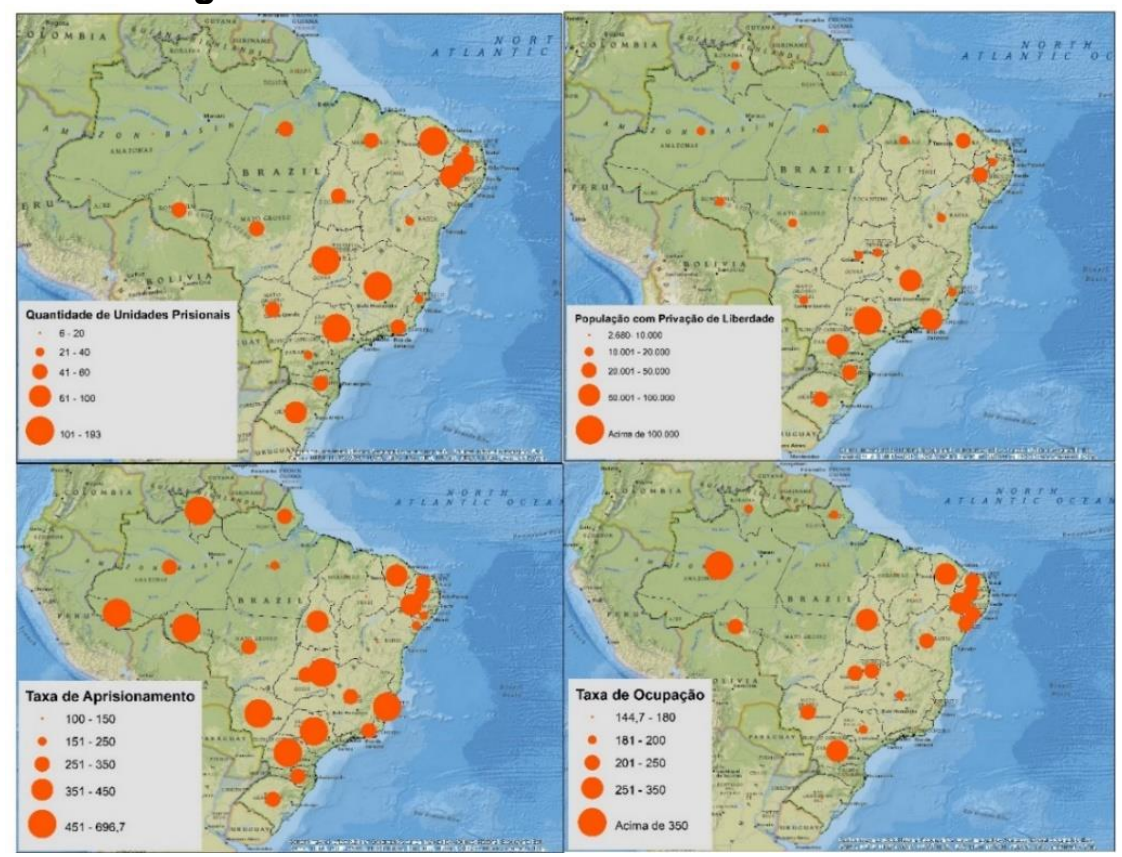

Disponível em: < Disponível em:< http://dados.mj.gov.br/dataset/infopen-levantamento-nacional-deinformacoes-penitenciarias. Acesso em: 15 ago. 2019.

O Brasil, possui atualmente segundo o Ministério da Justiça, cerca de 1.450 unidade prisionais. De acordo com o INFOPEN (2016), o maior quantitativo de unidades prisionais se concentra no sudeste do Brasil, com destaque para os estados de Minas Gerais (193) e São Paulo (164). Em outras regiões do País, destacam-se o Ceará (148) pelo Nordeste, Goiás (106) no Centro-Oeste, Rio Grande do Sul (99) pela região sul e Rondônia (53) ao Norte. Entre os estados, com menor quantitativo de presos estão o Distrito Federal e Roraima com 06 unidades prisionais, Sergipe (7), Amapá (8) e Alagoas (9).

Conforme dados do World Prison Brief ${ }^{4}$, o Brasil em relação as taxas de aprisionamento ${ }^{5}$, apresenta-se como a terceira maior população prisional do mundo, com índice superado somente pelos Estados Unidos (2,1 milhões de presos), e

\footnotetext{
${ }^{4}$ Base de dados construída pelo Institute for Criminal Policy Research, da Universidade de Londres (https://www.prisonstudies.org/world-prison-brief-data).

${ }^{5}$ Indica o número de pessoas presas para cada 100 mil habitantes. Para mais detalhes sobre taxas, ver Melo (2017).
} 
China (1,6 milhões de presos) (Figura 02). O Brasil, entre os anos de 2000 e 2017, registrou $212 \%$ de elevação em sua taxa de aprisionamento, colocando o País na vigésima posição em escala mundial (FBSP, 2019).

Figura 02- Evolução da taxa de aprisionamento no Brasil entre 2000 e 2017

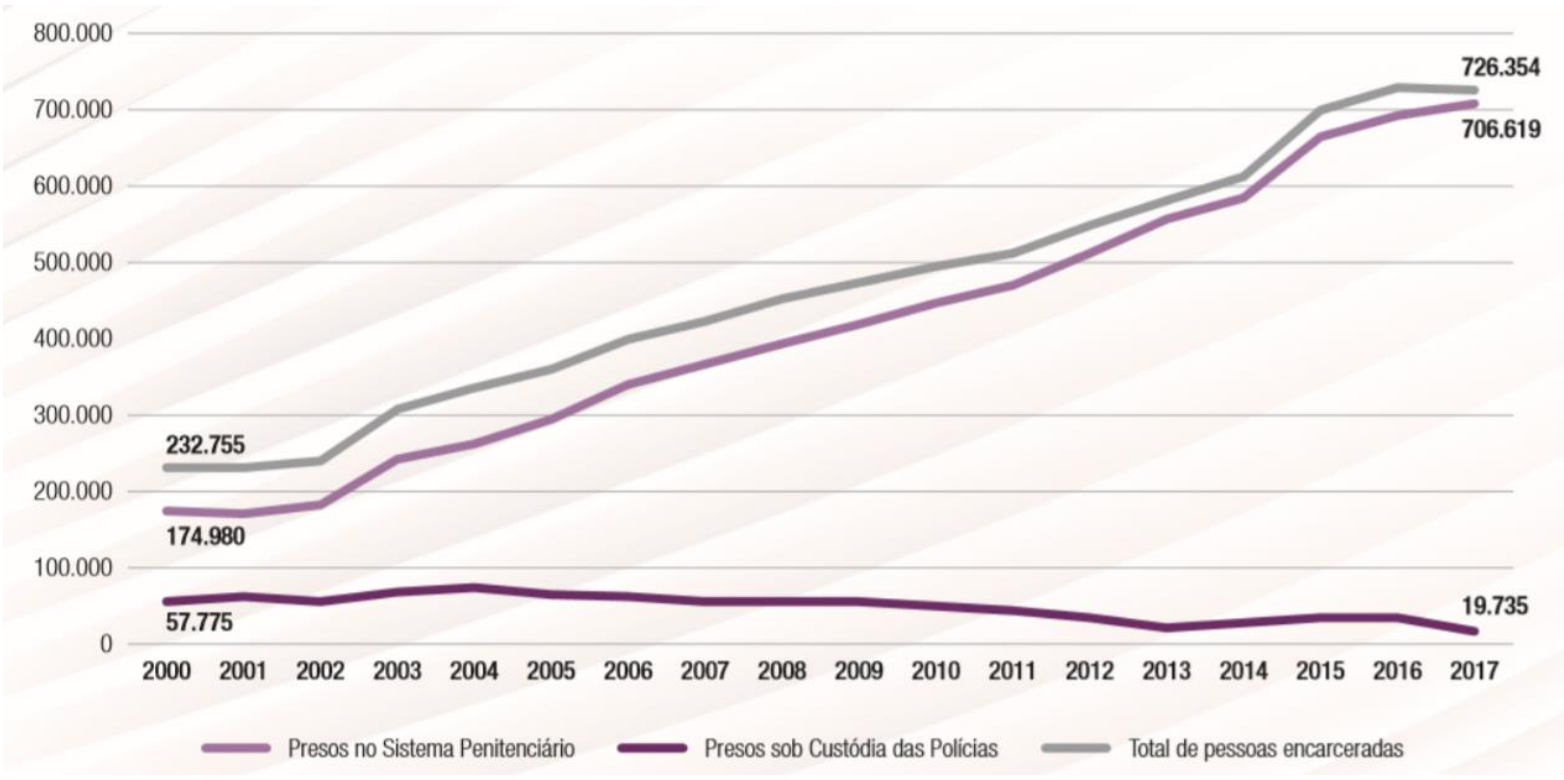

Fonte. FBSP, 2019.

Disponível em: < Disponível em:< http://dados.mj.gov.br/dataset/infopen-levantamento-nacional-deinformacoes-penitenciarias. Acesso em: 15 ago. 2019.

Para Sapori (2019), os estados que apresentam as taxas de aprisionamento e de ocupação mais elevadas, estão situados nas regiões Norte e Nordeste do País. Segundo o autor, essa dinâmica, influencia diretamente a significativa ocorrência de crises penitenciárias, massacres de presos e como demonstra Melo, Rocha e Masullo, (2019), a elevação das taxas de homicídios, com destaque para as capitais brasileiras que concentram a maior parcela dos presídios do País.

Entre os estados brasileiros, com as maiores taxas de aprisionamento destaca-se o Acre com 754,9 presos por 100 mil habitantes, seguido por Mato Grosso $(696,7)$ e Roraima $(606,1)$, enquanto que os estados da Bahia $(100,1)$, Piauí $(125,6)$ e Maranhão (127), registram os menores percentuais (INFOPEN, 2016). Em relação a taxa de ocupação dos presídios no Brasil, identifica-se índice de 165,1\%, com a situação mais problemática nos estados do Amazonas $(483,9)$, Ceará $(309,2)$ e Pernambuco $(300,6)$, já as menores taxas de ocupação, estão situadas no Espirito Santo $(144,7)$, Santa Catarina $(154,6)$ e Rio Grande do Sul $(156,5)$. 
Segundo o relatório do CNPM (MPMA, 2018), as taxas de ocupação dos presídios brasileiros são elevadas pelo grande quantitativo de presos provisórios, ou seja, todos aqueles sem julgamento transitado em julgado. $O$ País, apresenta percentuais que oscilam entre $35 \%$ e $36 \%$, taxas menores que as de países como a Suíça e em paridade com a Itália. Contudo, ressalta-se o significativo número de países, que não utilizam critérios metodológicos semelhantes ao Brasil. Conforme o referido relatório, a falta de procedimentos técnicos equânimes adotados pelos órgãos oficiais, coloca o País na $117^{a}$ posição em número de presos provisórios para cada 100.000 habitantes.

Para Dias e Manso (2018), esse contexto é reforçado pela limitada política de segurança pública, que não apresenta perspectivas para integrar ações de repressão qualificada com ações (de curto, médio e longo prazo) de prevenção. De acordo com os autores, essa realidade é alicerçada pela precária oferta de serviços públicos de qualidade (saneamento básico, saúde, educação etc.), e principalmente pela reduzida efetividade de políticas, focadas nas minorias e nos segmentos da população mais vulneráveis, à violência das facções e do sistema carcerário, ou seja, estamos falando dos jovens, pobres e negros (Figura 03).

Observa-se, que $55 \%$ da população carcerária brasileira é composta por jovens entre 18 e 29 anos (Figura 03). O declínio do sistema prisional brasileiro, além de ser capitaneado pela massiva presença de jovens entre os apenados, também apresenta influência sobre um significativo número de pessoas, que estão em contato com essa realidade carcerária de forma direta ou indireta. Para Machado e Guimarães (2014), isso amplia as desigualdades, considerando que os presídios brasileiros em geral proporcionam um ambiente degradante ao preso. Para autores, essa perspectiva é alicerçada pela superlotação, ausência de assistência médica, precariedade na alimentação e a falta de higiene que desencadeiam diversas doenças, diferentemente do que se estabelece na Constituição de 1988.

Figura 03- Faixa etária das pessoas privadas de liberdade no Brasil 


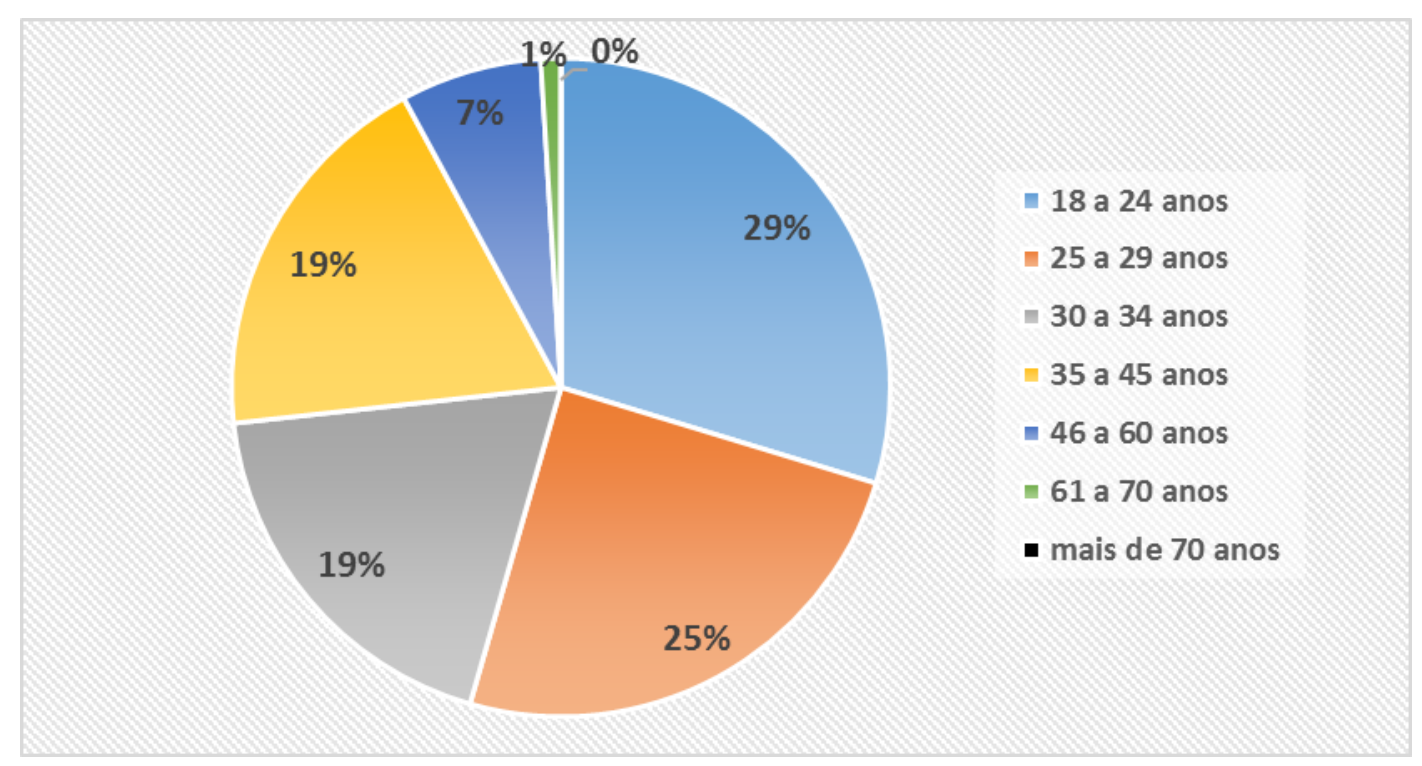

Fonte. INFOPEN, 2016.

Disponível em: < Disponível em:< http://dados.mj.gov.br/dataset/infopen-levantamento-nacional-deinformacoes-penitenciarias. Acesso em: 15 ago. 2019.

Esse cenário se complexifica, quando identificamos que $75 \%$ das pessoas privadas de liberdade no Brasil, são analfabetos ou possuem até o ensino fundamental completo, enquanto aproximadamente $1 \%$ da população carcerária possui ensino superior (Figura 04). Esse indicador, demonstra com clareza o perfil social e econômico das pessoas que entram e permanecem no sistema prisional brasileiro.

A realidade da educação nas prisões, tem demonstrado necessidades emergentes, que de diversas formas representam as fragilidades do sistema educacional brasileiro. Isso é solidificado conforme Craidy (2010), pelo reduzido quantitativo de detentos no Brasil, que possuem acesso à educação nas unidades prisionais, se compararmos com a realidade mundial. Verifica-se, segundo 0 INFOPEN (2016) que 578 entre as mais de 1.400 unidades prisionais brasileiras, não oferecem assistência educacional. Ao mesmo tempo, somente $14 \%$ dos presos e $26 \%$ das detentas, realizam algum tipo de trabalho interno.

Figura 04- Escolaridade das pessoas privadas de liberdade no Brasil 


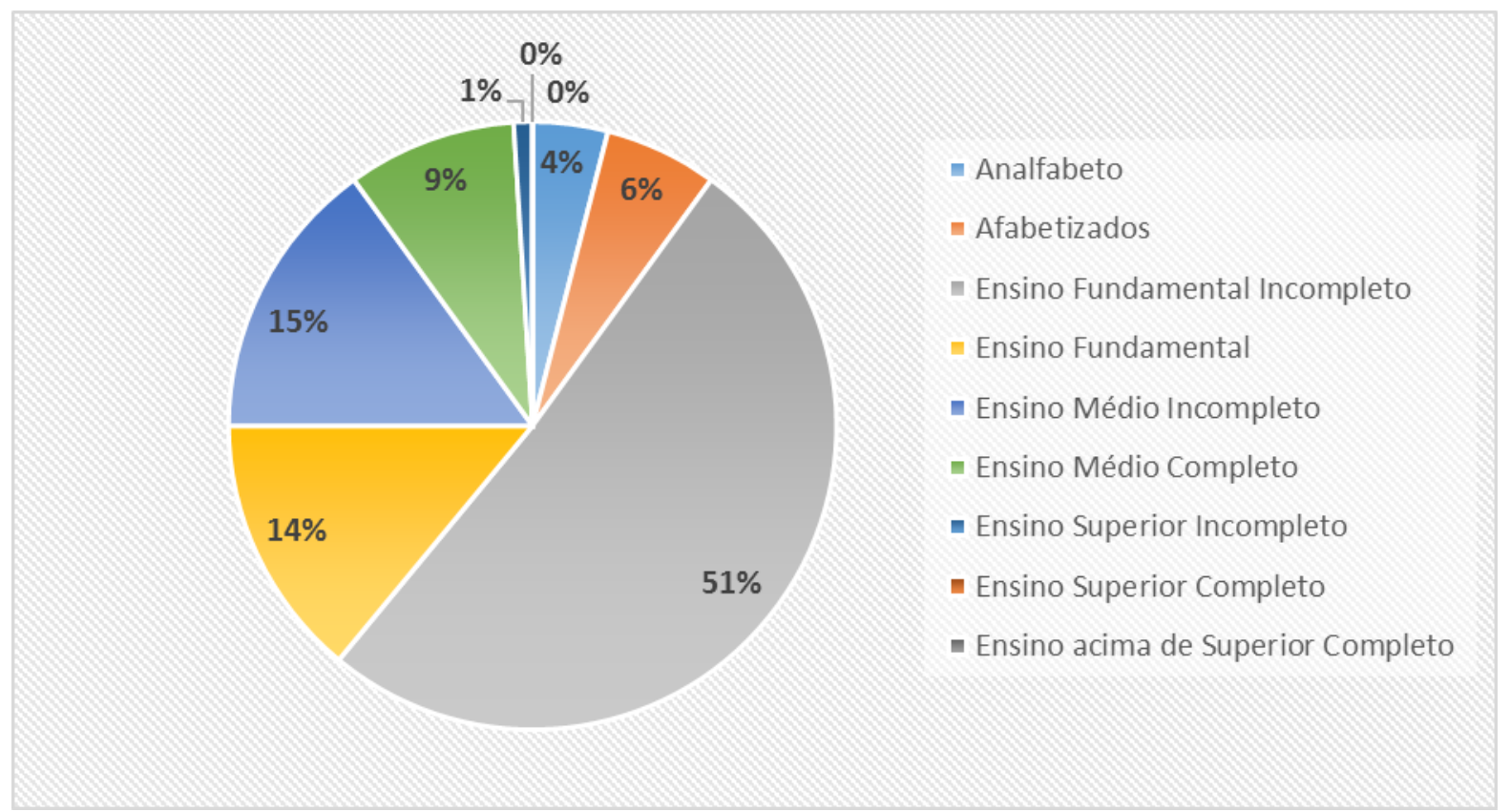

Fonte. INFOPEN, 2016.

Disponível em: < Disponível em:< http://dados.mj.gov.br/dataset/infopen-levantamento-nacional-deinformacoes-penitenciarias. Acesso em: 15 ago. 2019.

O contexto evidenciado, é contrário ao que prevê a Lei de Execução Penal (LEP), no 7.210 de 1984. O art $^{\circ} 17$, estabelece que a assistência educacional compreenderá a instrução escolar e a formação profissional do preso, enquanto o art $^{\circ} 18$, determina a obrigatoriedade do ensino de primeiro grau (ensino fundamental) e a integração com o sistema escolar estadual.

Para Machado e Guimarães (2014), é preciso ressaltar que as pessoas com privação de liberdade, assim como quaisquer outras, têm o direito humano à educação. Essa perspectiva, é preconizada na Declaração Universal dos Direitos Humanos em seu $\operatorname{art}^{\circ} 26$, onde se estabelece o direito à educação, cujo objetivo é o pleno desenvolvimento da pessoa e o fortalecimento do respeito aos direitos humanos.

As características do cárcere brasileiro, apresentam singularidades e significativa influência sobre o contexto regional do País. Para Monteiro e Cardoso (2013), o contexto apresentado demonstra uma política que privilegia o encarceramento, por se basear muitas vezes na pressão da sociedade e da mídia por mais segurança. Segundo os autores, isso impede a problematização e a reflexão sobre as causas que levaram a uma situação tão crítica. Para tanto, faz-se necessário conhecer essa dinâmica socioespacial e as pessoas que estão 
interligadas ao sistema prisional. Sob essa perspectiva, analisa-se a seguir de forma específica, o perfil social do sistema carcerário do Maranhão.

\section{Indicadores do Cárcere Maranhense}

O presente estudo, apresentou uma configuração do sistema prisional brasileiro, que se consolidou e vem se articulando conforme Manso e Dias (2017), por meio do mercado das drogas e facções supranacionais e regionais, formadas dentro dos presídios com graus diferentes de rivalidade e articulações. Infere-se a essa realidade, os diversos massacres nos presídios brasileiros, como um dos efeitos mais visíveis das articulações e da fluidez do crime organizado. Isso, comprova que o sistema prisional não é fim, mas pode se tornar o início e o meio desse ciclo esquizofrênico de violência, que se aprofunda em meio a nossa pseudodemocracia, e se complexifica através das singularidades territoriais, crises econômicas e desigualdades sociais.

Especificamente no Maranhão, verifica-se a partir de 2005, transformações no perfil socioespacial do sistema prisional, influenciado principalmente pela migração de facções criminosas, originárias da região Sudeste do País. Como resultado, observou-se a escalada de violência no Estado, e de forma específica na capital maranhense (Figura 05).

Observa-se, na figura 05 que no período entre 2000 a 2005 em São Luís, registrou-se relativa estabilidade das ocorrências de Crimes Violentos Letais Intencionais - CVLI ${ }^{6}$. Contudo, a partir do ano de 2006 percebe-se um crescimento expressivo nas notificações, alcançando em 6 anos um aumento de $107 \%$ dos casos de CVLI. Notadamente, consolida-se um período de crise na segurança pública do Maranhão, com o colapso do sistema prisional. Uma série de eventos no complexo prisional de Pedrinhas, desencadeou o crescimento exponencial em 2012 com ápice em 2013, resultando em uma elevação de aproximadamente $47 \%$ das ocorrências dos crimes letais.

\footnotetext{
6 A sigla CVLI foi criada em 2006 pela Secretaria Nacional de Segurança Pública (SENASP), vinculada ao Ministério da Justiça (MJ). Esta sintetização dos dados de violência é composta por homicídio doloso, lesão corporal seguida de morte e roubo seguido de morte "latrocínio".
} 
Figura 05- Comparativo entre quantitativo de ocorrências e incidência de CVLI em São Luís por 100 mil habitantes, entre 2000 a 2019.

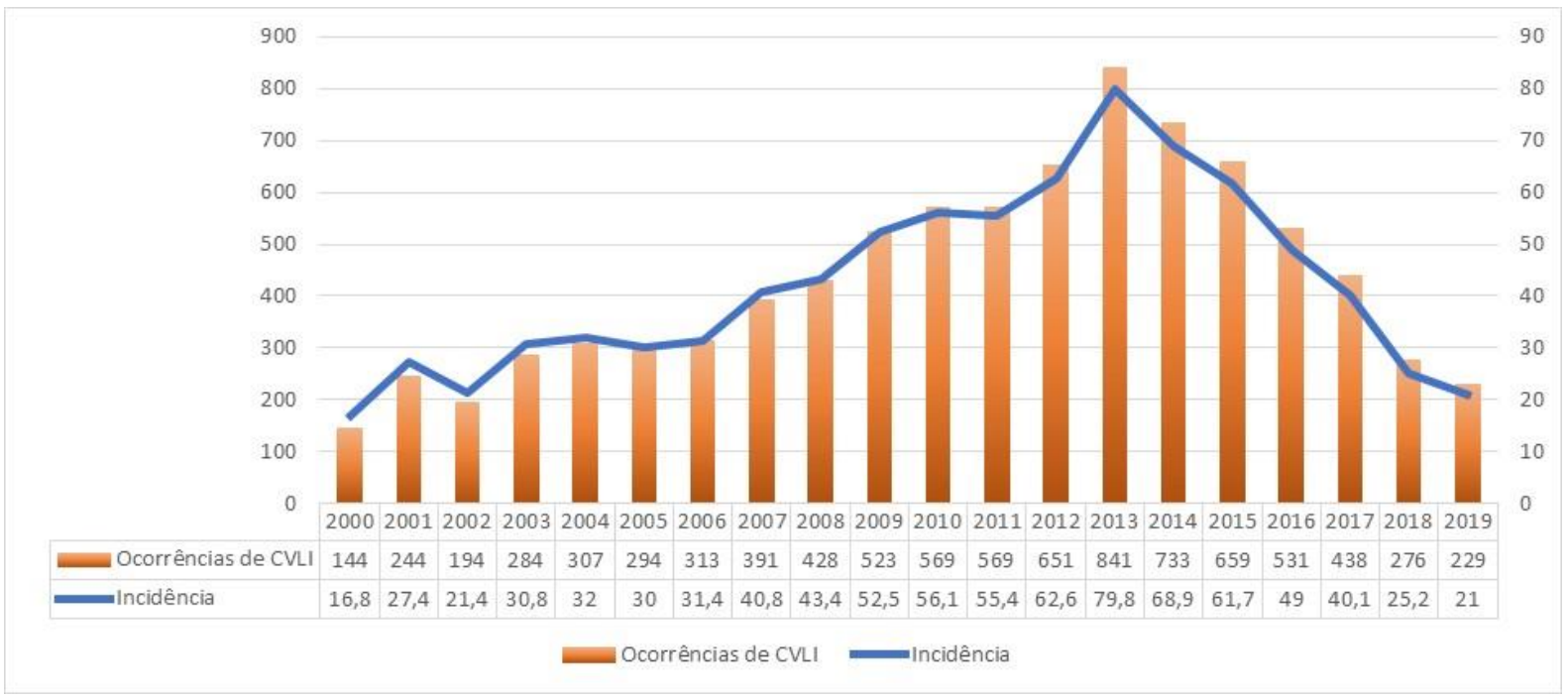

Fonte. SSP, 2020.

Após 10 anos de ampliação progressiva dos casos de CVLI, observa-se em 2015, consolidação na redução das ocorrências, seguindo tendência nacional. Essa realidade se perpetuou, com a diminuição de 58\% no período de 2015 e 2019. Como resultado, São Luís foi a única capital do nordeste brasileiro a deixar a lista das 50 cidades mais violentas do mundo em 2017, conforme a organização de sociedade civil mexicana de Segurança, Justiça e Paz. Nesse período de redução sucessiva da violência letal, o Maranhão registrou considerável elevação da taxa de encarceramento no sistema prisional, bem como redução da taxa de ocupação originária da construção de novos presídios no Estado, o que ampliou significativamente as vagas totais disponíveis nas unidades prisionais - UPR (Figura 06).

Conforme Monteiro e Cardoso (2013), o crescimento das taxas de encarceramento no Brasil e especificamente nas unidades da federação, foi acompanhado de formas mais severas do aparato repressivo. Para alguns, os resultados apresentados, podem reforçar o uso de teses que segundo Kanh (2018), já se mostraram equivocadas em curto, médio e longo prazo, para se alcançar a redução da criminalidade. Entre estás, destaca-se a necessidade de ampliação massiva das taxas de encarceramento.

Figura 06- Taxa de Ocupação e de Encarceramento no Maranhão entre 2014 e 2018 


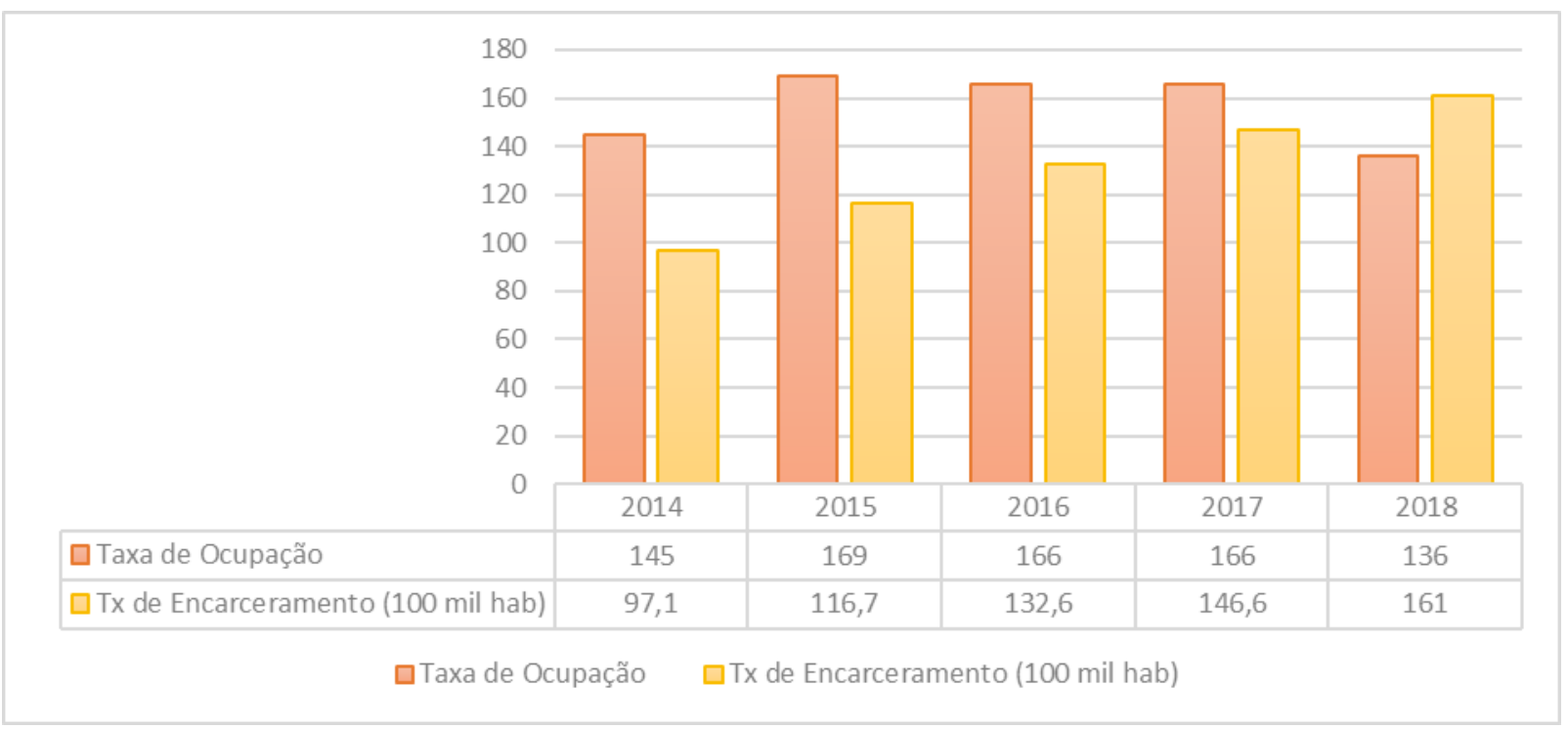

Fonte. INFOPEN/SEAP, 2018.

Sobre a perspectiva supracitada, Menezes e Uchoa (2014) afirmam, que mesmo em países como os Estados Unidos, o efeito dissuasório da polícia e da Justiça tem sido posto em questão, considerando que a população carcerária permanece sendo elevada, sem impacto significativo sobre as taxas de criminalidade. Na verdade, exemplos como este, fazem Lemgruber (2001) reforçar que não existe estudos conclusivos, que demonstre inequivocamente os impactos positivos da ampliação das taxas de encarceramento, para a redução geral da criminalidade ou mesmo na diminuição dos crimes mais grave.

Desse modo, faz-se necessário reforçar que a consolidação da redução dos registros de CVLI no Maranhão, teve como propulsor as ações do Governo do Estado ligadas a ampliação do efetivo, requalificação de estrutura, qualificação e valorização policial, alinhado a implementação de políticas públicas ligadas a infraestrutura (requalificação de vias na área urbana e rural, reformas de escolas, construção de moradias e de áreas de lazer), bem como a mediação de conflitos, através da ampliação da regularização fundiária, ações afirmativas ${ }^{7} \mathrm{e}$ inclusão social.

\footnotetext{
${ }^{7}$ Ações afirmativas são medidas especiais e temporárias, tomadas pelo Estado e/ou pela iniciativa privada, com o objetivo de eliminar desigualdades historicamente acumuladas, garantindo a igualdade de oportunidade e tratamento, bem como compensar perdas provocadas pela discriminação e marginalização, por motivos raciais, étnicos, religiosos, de gênero e outros (MINISTÉRIO DA JUSTIÇA, 1996).
} 
Como relatado anteriormente, entre 2014 e 2020 registrou-se um aumento de $33 \%$ do quantitativo de UPR, ampliando em 110,9\% o número de vagas no sistema carcerário do Estado (Figura 07).

Figura 07- Unidade Prisionais e Vagas do sistema carcerário do Maranhão (2014 2018)

\begin{tabular}{|c|c|c|c|c|c|c|}
\hline \multicolumn{6}{|l|}{50} & 9.000 \\
\hline \multicolumn{6}{|l|}{45} & 8.000 \\
\hline \multicolumn{6}{|l|}{$\begin{array}{l}40 \\
35\end{array}$} & 7.000 \\
\hline \multicolumn{7}{|r|}{6.000} \\
\hline \multicolumn{7}{|r|}{5.000} \\
\hline \multicolumn{7}{|r|}{4.000} \\
\hline \multicolumn{7}{|r|}{3.000} \\
\hline \multicolumn{7}{|r|}{2.000} \\
\hline \multicolumn{7}{|r|}{1.000} \\
\hline 0 & 2014 & 2015 & 2016 & 2017 & 2018 & 0 \\
\hline Unidades Prisionais & 33 & 34 & 39 & 44 & 44 & \\
\hline Vagas Totais & 4.589 & 4.782 & 5.540 & 6.187 & 7.869 & \\
\hline
\end{tabular}

Fonte. SEAP, 2018.

Em 2018, o Maranhão passou a contar com 45 UPRs e 7 APACs. Entre estás, 14 UPR estão localizadas nos municípios de São Luís e Paço do Lumiar, concentrando 46,6\% (5.308) dos presos do Estado, enquanto que ao Leste (Caxias, Timom, Codó e Coroatá) situam-se 13\% e na região Sudoeste 7,5\% (Imperatriz, Açailândia, Davinópolis e Porto Franco) da população carcerária lotada nos presídios maranhenses (Figura 08). 
Figura 08- Concentração de presos nas unidades prisionais do Maranhão.

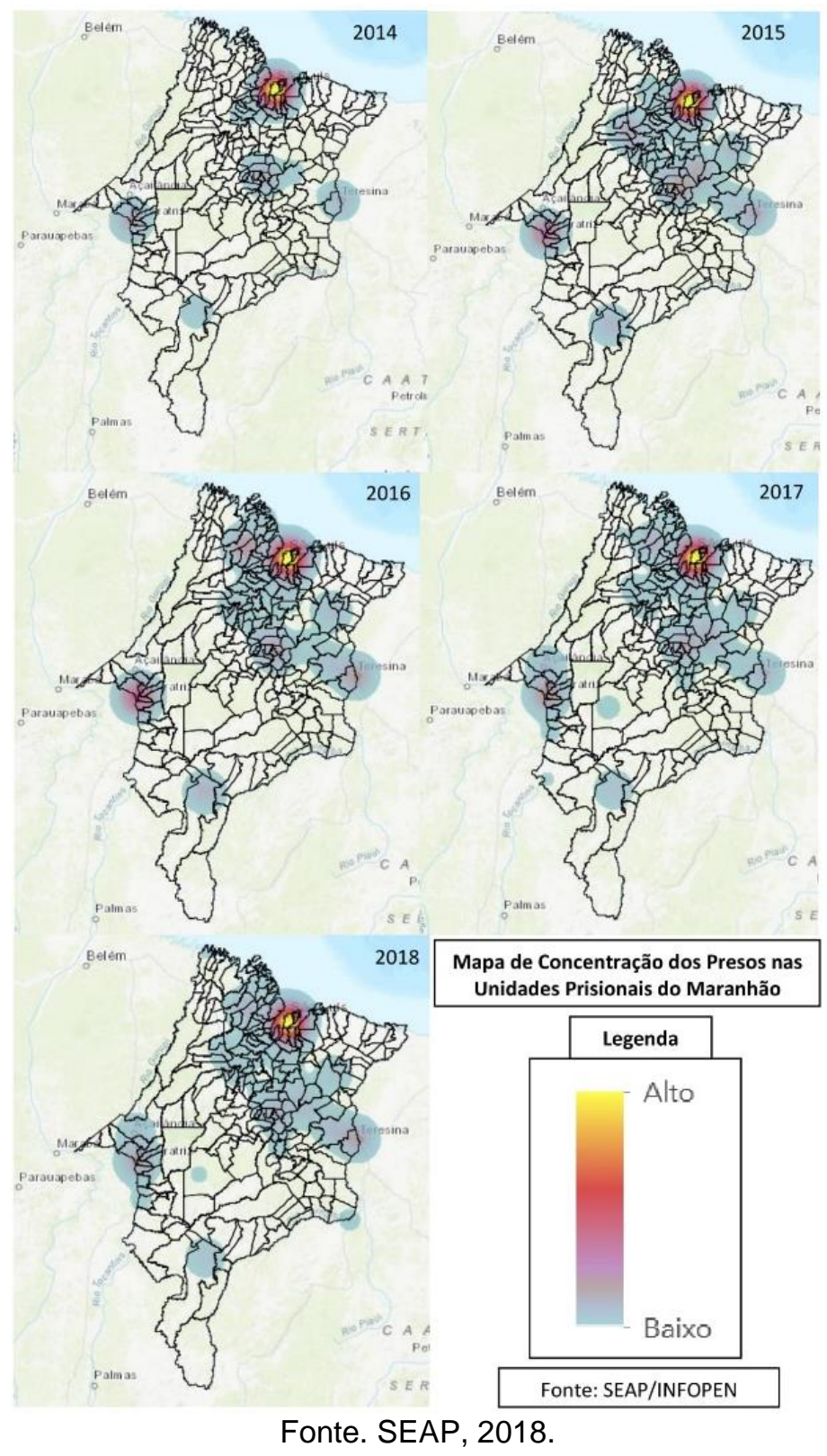

Verifica-se, que a construção de novos presídios no período analisado em municípios do interior do Estado, reduziram a centralização dos presos na capital maranhense e elevaram o quantitativo de pessoas com privação de liberdade, em municípios como Balsas, Caxias, Codó, Coroatá, Imperatriz e Timom. O sistema prisional do Maranhão segundo a SEAP (2018), alcançou em 2018 uma população carcerária de 11.388, destes 209 apenados estavam situados em Associações de Proteção e Assistência aos Condenados - APAC $^{8}$ e 11.179 com privação de

\footnotetext{
8 A APAC é uma entidade civil de direito privado, sem fins lucrativos, com personalidade jurídica própria, dedicada à recuperação e reintegração social dos condenados às penas privativas de liberdade.
} 
liberdade, para um total de 7.859 vagas, ou seja, um déficit de 3.519 vagas (Figura 09).

Figura 09- Características da população carcerária do Maranhão

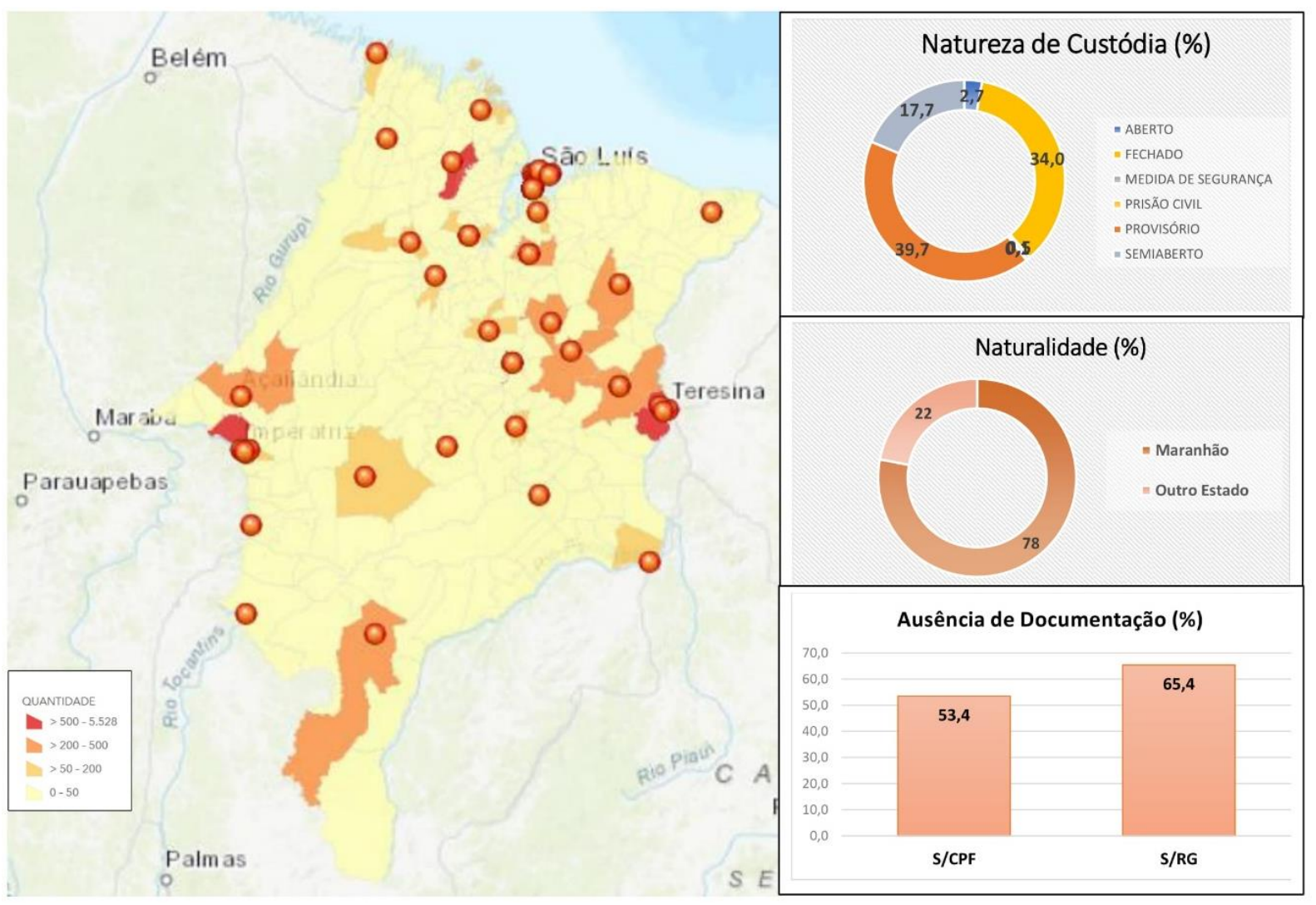

Fonte. SEAP, 2018.

Em 2019, identifica-se que 35,9\% da população carcerária do Maranhão era composta por presos em regime provisório. Ressalta-se o art. $84^{\circ}$ da LEP, este prevê que o preso provisório deve ficar separado dos demais que possuem pena já transitado e julgado.

Segundo estudo realizado pelo Instituto Sou da Paz (2013), o enorme contingente de presos em regime provisório é um dos mais graves problemas do sistema carcerário brasileiro, considerando que se leva aproximadamente 7 meses para ocorrer o julgamento, destes apenas 18,6\% dos casos cometeram crimes graves para ser mantido em regime fechado. Entre os condenados $30 \%$ dos casos, recebem uma pena em que tem que prestar serviços comunitários, pagar uma multa ou apenas dormir na prisão. Nesses casos, segundo o estudo citado, faz-se necessário considerar se a prisão foi indevida, pois mesmo antes de ser condenado o réu cumpriu uma pena muito mais grave do que merecia. 
O grande número de presos provisórios (Salla, 2003), agrava um dos problemas crônicos, a superlotação nos presídios, por ampliar o déficit de vagas do sistema prisional. Por outro lado, verifica-se que $40 \%$ dos presos do Maranhão cumprem regime fechado, 20,4\% semiaberto e somente 2,9\% estão em regime aberto com a possibilidade de deixar a UPR durante o dia, com previsão de retorno no período noturno (SEAP, 2019).

De acordo com Assis (2007), esse processo é solidificado pela demora em se conceder os benefícios aos apenados, que fazem jus à progressão de regime, ou em soltar os presos que saldaram o cômputo de sua pena. Para o autor, essa situação decorre da própria negligência e/ou ineficiência das instituições públicas responsáveis pela execução penal, ampliando a concentração de presos em determinadas comarcas.

Sobre a questão da superlotação nos presídios, Cescon e Baeninger (2010) expõe a necessidade urgente de se resolver o processo de concentração de presos, oriundos do interior dos estados na capital, bem como a imigração de presos de outras regiões do País. Os autores, reconhecem esse fenômeno como "inchaço artificial da população carcerária".

O inchaço artificial dos presídios ressaltado, além de gerar grande fluxo de visitantes e transformar áreas anteriormente isoladas, em pontos de centralidades regionais, geram emprego e renda, que passa a circular no comércio local e das cidades vizinhas. No Maranhão, identifica-se que $22 \%$ dos apenados não nasceram no Estado, entre estes, a maior parcela são originários de estados que possuem limites territoriais como o Pará, Piauí e Tocantins. Contudo, observa-se presos com naturalidade de estados das regiões Centro-Oeste, Sudeste e Sul do País, como Goiás, São Paulo, Santa Catarina e outros.

Esse contexto, vem sendo solidificado pela migração das facções do Sudeste para o Norte e Nordeste do País. Entre os apenados maranhense, verifica-se que 44\% são originários de apenas 5 municípios do Estado, entre eles estão a capital maranhense (32\%), Imperatriz (5,4\%), Caxias (2,5\%), Bacabal (2\%) e Codó (2\%).

Outro grave problema, que se identifica nos presídios do Maranhão, é justamente a significativa parcela de presos que não possuem documentos como Registro Geral - RG e Cadastro de Pessoa Física - CPF, seja por extravio ou por acesso a informação. Conforme dados fornecidos pela SEAP em 2018, cerca de 
53\% dos presos no sistema penitenciário do Estado não possuíam CPF, enquanto que $65,4 \%$ afirmavam não ter RG.

Ressalta-se, que ausência destes documentos, impossibilita abrir contas em bancos, declarar imposto de renda, ser beneficiário de programas sociais do governo, ter carteira de trabalho assinada ou mesmo participar regularmente de pleitos eleitorais. Isso, amplifica os problemas ligados a ressocialização e as questões sociais, que estão intrinsecamente relacionados ao contexto do sistema prisional evidenciado.

$\mathrm{Na}$ figura 10 a seguir, verifica-se dados referentes as características sociais da população carcerária do Estado, como sexo, escolaridade e cor. No que tange, ao sexo dos apenados, observa-se que $96 \%$ são homens (entre estes somente $2,3 \%$ afirmam ser homossexuais).

Mesmo que somente $4 \%$ da população prisional, seja composta por mulheres, destaca-se que a grande maioria destas, assim como os homens integram grupos de vulnerabilidade social, considerando que $53,3 \%$ possuem idade entre 18 e 29 anos, são chefes de família com uma média de dois filhos, além de apresentar escolaridade baixa e conduta delituosa que se caracteriza pela menor gravidade, geralmente presas por crimes relacionados à questão de drogas (SEAP, 2018; INSTITUTO SOU DA PAZ, 2011). 
Figura 10- Características sociais da população carcerária do Maranhão

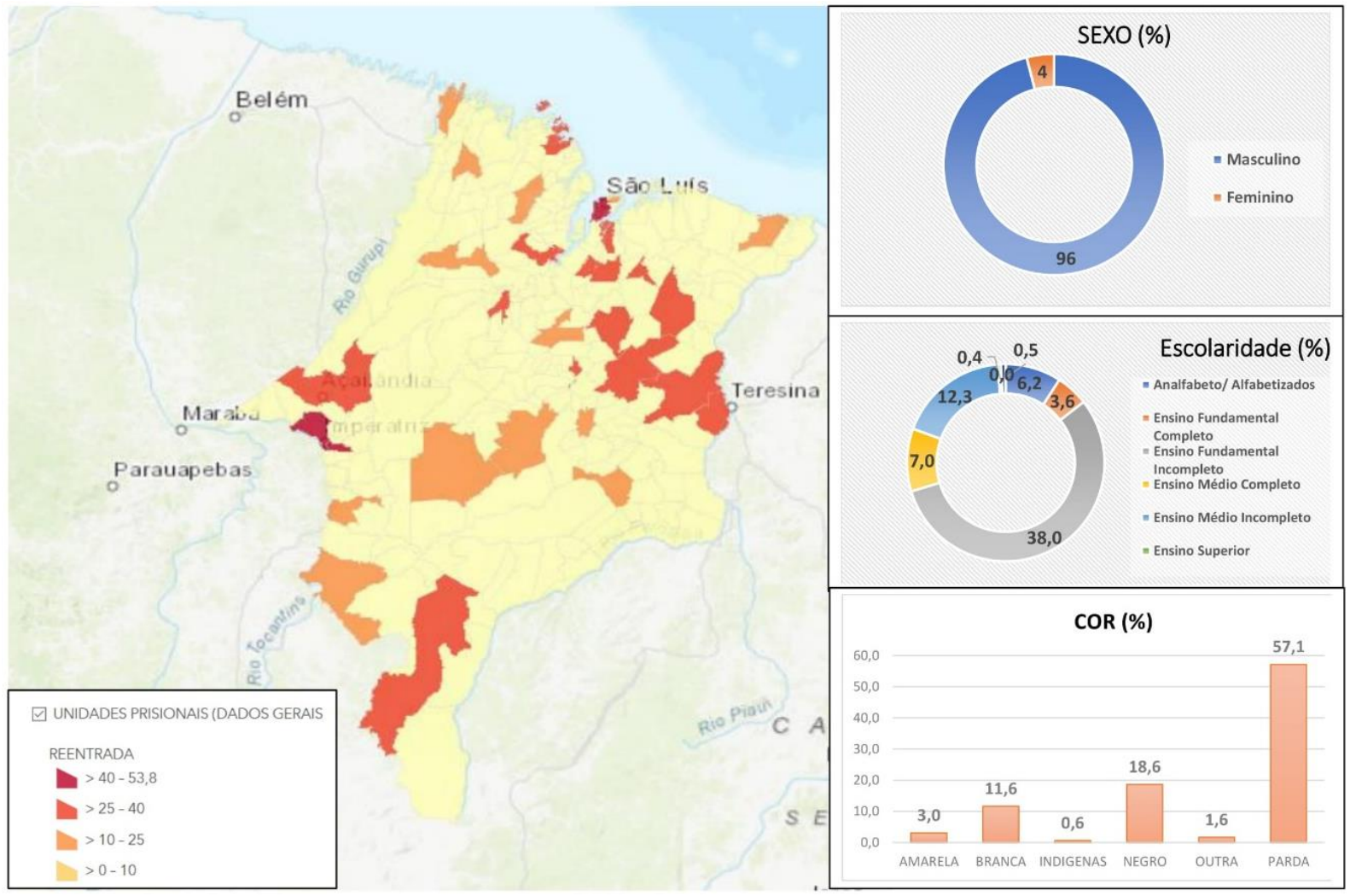

Fonte. SEAP, 2018.

Apesar de ter se convencionado afirmar, que ao mesmo tempo em que os jovens são vítimas de homicídios, eles também são os que mais matam. Para Monteiro e Cardos (2013), os jovens não são as principais vítimas de homicídios, são também os alvos mais vulneráveis ao processo de criminalização e seletividade do sistema penal.

Outra questão a ser ressaltada, é o baixo nível escolar, que amplia a vulnerabilidade das pessoas dentro do sistema prisional. No Maranhão, identifica-se que $47,9 \%$ dos presos possuem até o ensino fundamental, enquanto somente $7 \%$, contam com o ensino médio completo e $0,4 \%$ ensino superior. No sistema carcerário do Maranhão, de acordo com a SEAP (2018), foi encontrado apenas um preso com pós-graduação cumprindo pena.

Realidade semelhante foi identificada por Wacquant (2008), ao analisar o sistema penitenciário francês e norte-americano. Segundo o autor, o sistema penitenciário no modelo atual, serve como um depósito de desempregados cumprindo um papel de limpeza e higienização dos excluídos da sociedade, formando uma massa de pessoas de baixa escolaridade. Isso, nos faz refletir sobre 
a atual política de execução penal, que privilegia o encarceramento em massa, a construção de novos presídios e a criação de mais vagas em detrimento de outras políticas públicas (IPEA, 2015). Sobre essa questão Baratta (1990), afirma que o modelo prisional brasileiro, é de fato incapaz de promover a ressocialização, se produzido de fato obstáculos ao alcance deste objetivo.

A baixa escolaridade dos apenados, influencia questões como 0 alto percentual de reentrada ${ }^{9}$ no sistema prisional. Segundo dados da SEAP (2019), aproximadamente $47,5 \%$ das pessoas que passam pelos presídios do Estado retornam, seja pelo mesmo crime anteriormente cometido, ou por cometer outro ato criminoso. Nitidamente, isso revela que a reinserção ou ressocialização do indivíduo não é cumprida.

Nesse contexto, é importante frisar as importantes ações desenvolvidas pelo Governo do Estado no sistema carcerário do Maranhão, por meio da SEAP. Referente ao setor educacional, a Administração Penitenciária juntamente com a Secretarias de Estado em 2019 certificou 737 detentos do sistema prisional maranhense em cursos profissionalizantes. Esses cursos, foram ofertados pelo Instituto Estadual de Educação, Ciência e Tecnologia do Maranhão (IEMA) dentro das unidades prisionais em 19 municípios maranhenses. Ressalta-se, que entre os apenados, 431 foram aprovados no Exame Nacional do Ensino Médio - ENEM em 2018.

Em relação a cor da população carcerária, observa-se que $80 \%$ se reconhece como negro, pardo ou amarelo e somente $11,6 \%$ são brancos. Isso, reforça a vulnerabilidade social, e evidencia a diferença marcante entre os negros e os brancos no Maranhão e no Brasil. Mesmo com a maior parcela da sociedade maranhense, sendo composta por pardos e negros (78\% da população maranhense segundo censo IBGE, 2010), concordamos com Coelho (2005), quando o autor afirma que os estereótipos de cor parecem funcionar efetivamente, no que se refere ao acesso diferencial à justiça por meio de marcadores sociais.

Coaduna com essa perspectiva Assis (2007), em seu estudo sobre a realidade do sistema penitenciário brasileiro. O autor, afirma que a sociedade se esquece ou não percebe que $95 \%$ da população carcerária brasileira, é oriunda da

\footnotetext{
${ }^{9}$ Reentrada ou reincidência penitenciária, segundo IPEA (2015) compreende o sujeito que, tendo já cumprido pena, tenha sido recolhido novamente em estabelecimento penal.
} 
classe dos excluídos sociais, pobres, desempregados e analfabetos, que, de certa forma, estão mais expostos ao crime por não terem melhores oportunidades sociais.

\section{Considerações Finais}

O objetivo deste artigo foi o de caracterizar o perfil socioeconômico das unidades prisionais e consolidar um acervo de informações - com base em critérios, padrões e linguagens de fácil compreensão e utilização - que forneça subsídios para a proposição de políticas públicas e estratégias de monitoramento, aperfeiçoamento e fiscalização do Sistema Carcerário do Maranhão.

Assim como no Brasil, o Maranhão apresenta um aumento vertiginoso da população carcerária, resultante de uma política de repressão e criminalização à pobreza. Esse modelo, parte da premissa que o encarceramento em massa, reduz as ocorrências criminais letais e não letais. No entanto, é preciso destacar que a segurança pública influencia e é influenciada por fatores socioeconômicos e políticas públicas ligadas a educação, saúde, lazer e turismo. Desse modo, para quebrar esse ciclo esquizofrênico que o sistema prisional brasileiro se encontra, é preciso desenvolver ações capazes de integrar políticas de inclusão social aos mecanismos de segurança pública.

Para tanto, devesse considerar aspectos identificados no presente estudo, como fatores que ampliam a vulnerabilidade das pessoas dentro e fora do sistema prisional e a classe dos excluídos, ou seja, pobres, desempregados e analfabetos.

Por fim, verifica-se que ao agrupar as informações sobre o perfil socioeconômico do sistema carcerário do Estado, considerando aspectos como taxas de ocupação e aprisionamento, natureza de custódia, naturalidade, cor, sexo e escolaridade, apresenta-se os verdadeiros "clientes" das prisões, bem como fornece subsídios para a proposição de políticas públicas e estratégias, oferecendo uma necessária reflexão sobre a naturalização do perfil social do cárcere brasileiro e maranhense.

\section{REFERÊNCIAS}

ASSIS, R. D. A Realidade atual do sistema penitenciário brasileiro. Revista CEJ. XI. № 39. Brasília. 2007. p. $74-78$.

BORGES, J. Encarceramento em massa. Pólen Produção Editorial LTDA, 2019. 
CALLEGARI, A. Prisão deve ser vista como exceção, e não como regra. IN: O sistema prisional brasileiro: um espelho da sociedade. (Orgs) WOLFF, M. P.; BARRETO, V. de P.; VEIGA-NETO, A. Revista do Instituto Humanitas Unisinos (On-line). IX. 2009. 56p.

CECCATO, V.; MELO, S. N.; KAHN, T. Trends and patterns of police-related deaths in Brazil. In: The Palgrave Handbook of Criminology and the Global South. Palgrave Macmillan, Cham, 2018. p. 521-550.

CESCON, F. R. P.; BAENINGER, R. Cidades Carcerárias: Migração e Presídios em Regiões de São Paulo. ENCONTRO NACIONAL DE ESTUDOS POPULACIONAIS, 17. Anais [...]. Caxambu - MG. 2010. p. $1-15$.

CRAIDY, C. M. (Org.). Educação em prisões: direito e desafio. Porto Alegre: UFRGS. 2010.

DIAS, C. N.; MANSO, B. P. Facções Prisionais no Brasil. In: Anuário Brasileiro de Segurança Pública 2017. Fórum Brasileiro de Segurança Pública. 2018. p. 6 - 7.

FBSP. Fórum Brasileiro de Segurança Pública. Anuário Brasileiro de Segurança Pública 2019. 2019. 206p.

CARVALHO NETO, R. R. Indiferença Estatal e Social: a situação de abandono das mulheres no cumprimento da pena. In: A visão do Ministério Público sobre o sistema prisional brasileiro. Conselho Nacional do Ministério Público - CNPM. 2016. 346p.

DOTTI, René Ariel. A crise do Sistema Penitenciário. RD. Artigos de Direito. 2003. p. 1 15.

DULLIUS, A. A.; HARTMANN, J. A. M. Análise do Sistema Prisional Brasileiro. In: Âmbito Jurídico. RN. XIV. N 95. 2011. Disponível em: < http://www.ambitojuridico.com.br/site/index.php?artigo_id=10878\&n_link=revista_artigos_leitura $>$. Acesso em junho de 2019.

INSTITUTO SOU DA PAZ. Penitenciárias são feitas por Homens e para Homens. Relatório Técnico. 2011. 11p.

INFOPEN. Levantamento Nacional de Informações Penitenciárias. Disponível em: < https:// http://dados.mi.gov.br/dataset/infopen-levantamento-nacional-de-informacoespenitenciarias >. Acesso em: 15 ago. 2019.

IPEA - Instituto de Pesquisa Econômica Aplicada. Reincidência Criminal no Brasil. Relatório de Pesquisa. IPEA - Instituto de Pesquisa Econômica Aplicada. Brasília. 2015. 162p.

KAHN, T. Seis teses equivocadas sobre a criminalidade brasileira. 2018. Disponível em: http://tuliokahn.blogspot.com/. Acesso em: 12 de novembro de 2018.

BRASIL. Lei Federal № 7.210 de 11de julho de 1984. Lei de Execução Penal. 1984. Disponível em: http://www.planalto.gov.br/ccivil 03/leis/l7210.htm. Acesso em: 07 de outubro de 2019.

LEMGRUBER, J. Verdades e mentiras sobre o sistema de justiça criminal. Revista CEJ, Brasília, n. 15. 2001. p. 12-29. 
MACHADO, N. O.; GUIMARÃES, I. S. A Realidade do Sistema Prisional Brasileiro e o Princípio da Dignidade da Pessoa Humana. Revista Eletrônica de Iniciação Científica. Itajaí, Centro de Ciências Sociais e Jurídicas da UNIVALI. v. 5, n.1, 2014. p. 566-581.

MENEZES, T. A.; UCHOA, C. F. Spillover espacial da criminalidade: uma aplicação de painel espacial, para os estados brasileiros. ENCONTRO NACIONAL DE ECONOMIA, 40., 2014. Anais [...]. ANPEC - Associação Nacional dos Centros de Pós-Graduação em Economia. Associação Brasileira dos Programas de Pós-Graduação em Economia. 2014.

MELO, S. N. Geografia do Crime: análise espacial da criminalidade no município de Campinas-SP. Dissertação. Campinas: Instituto de Geociências, Universidade Estadual de Campinas, 2017.

MELO, S. N., ROCHA, J.; MASULLO, Y. A. G. Análise longitudinal dos fatores associados a epidemia/endemia de homicídios nas capitais brasileiras. CONFINS (PARIS). № 42. 2019.

MONTEIRO, F. M.; CARDOSO, G. R. A seletividade do sistema prisional brasileiro e o perfil da população carcerária: um debate oportuno. CIVITAS. v. 13. $n^{\circ} 1$. Porto Alegre. 2013. p. 93 $-117$.

MPMA - Ministério Público do Maranhão. Superencarceramento vs Superimpunidade. CAOP - CRIM - Centro de Apoio Operacional Criminal. São Luís. 2018. 20p.

PASSOS, E. H.; SOUZA, T. P. Redução de danos e saúde pública: construções alternativas à política global de" guerra às drogas". Psicologia \& Sociedade, v. 23, n. 1, p. 154-162, 2011.

SALLA, F. Os impasses da democracia brasileira: o balanço de uma década de políticas para as prisões no Brasil. Lusotopie, Bordeaux, 2003.

SAPORI, L. F. Crônicas de uma Falência auto cumprida. In: Anuário Brasileiro de

Segurança Pública 2019. Fórum Brasileiro de Segurança Pública. 2019. p. 200 - 202.

SEAP. Secretaria de Estado de Administração Penitenciária. Banco de Dados. Governo do Estado do Maranhão. 2018.

PEDROSO, R. C. Utopias Penitenciárias Projetos Jurídicos e Realidade Carcerária no Brasil. Revista de História. FFLCH - USP. N 136. 1997. p. $121-137$.

WACQUANT, L. A aberração carcerária à moda francesa. Revista de Ciências Sociais. Rio de Janeiro, v. 47, n. 2. 2004. p. 215-232.

\section{NOTAS DE AUTOR}

\section{CONTRIBUIÇÃO DE AUTORIA}

Yata Anderson Gonzaga Masullo - Concepção e elaboração do manuscrito. Janderson Rocha - Coleta e análise de dados.

Silas Nogueira de Melo - Revisão e aprovação da versão final do trabalho.

\section{FINANCIAMENTO}

Fundação de Amparo à Pesquisa e ao Desenvolvimento Científico e Tecnológico do Maranhão - FAPEMA, processo 00992/19.

Fundação de Amparo à Pesquisa e ao Desenvolvimento Científico e Tecnológico do Maranhão - FAPEMA, DTI06218/18 
Fundação de Amparo à Pesquisa e ao Desenvolvimento Científico e Tecnológico do Maranhão - FAPEMA, CIDADES-04775/18

\section{CONSENTIMENTO DE USO DE IMAGEM}

Não se aplica.

\section{APROVAÇÃO DE COMITÊ DE ÉTICA EM PESQUISA}

Não se aplica.

\section{CONFLITO DE INTERESSES}

A presente pesquisa não possui conflitos de interesse.

\section{LICENÇA DE USO}

Este artigo está licenciado sob a Licença Creative Commons CC-BY. Com essa licença você pode compartilhar, adaptar, criar para qualquer fim, desde que atribua a autoria da obra.

\section{HISTÓRICO}

Recebido em: 20-11-2019

Aprovado em: 22-05-2020 